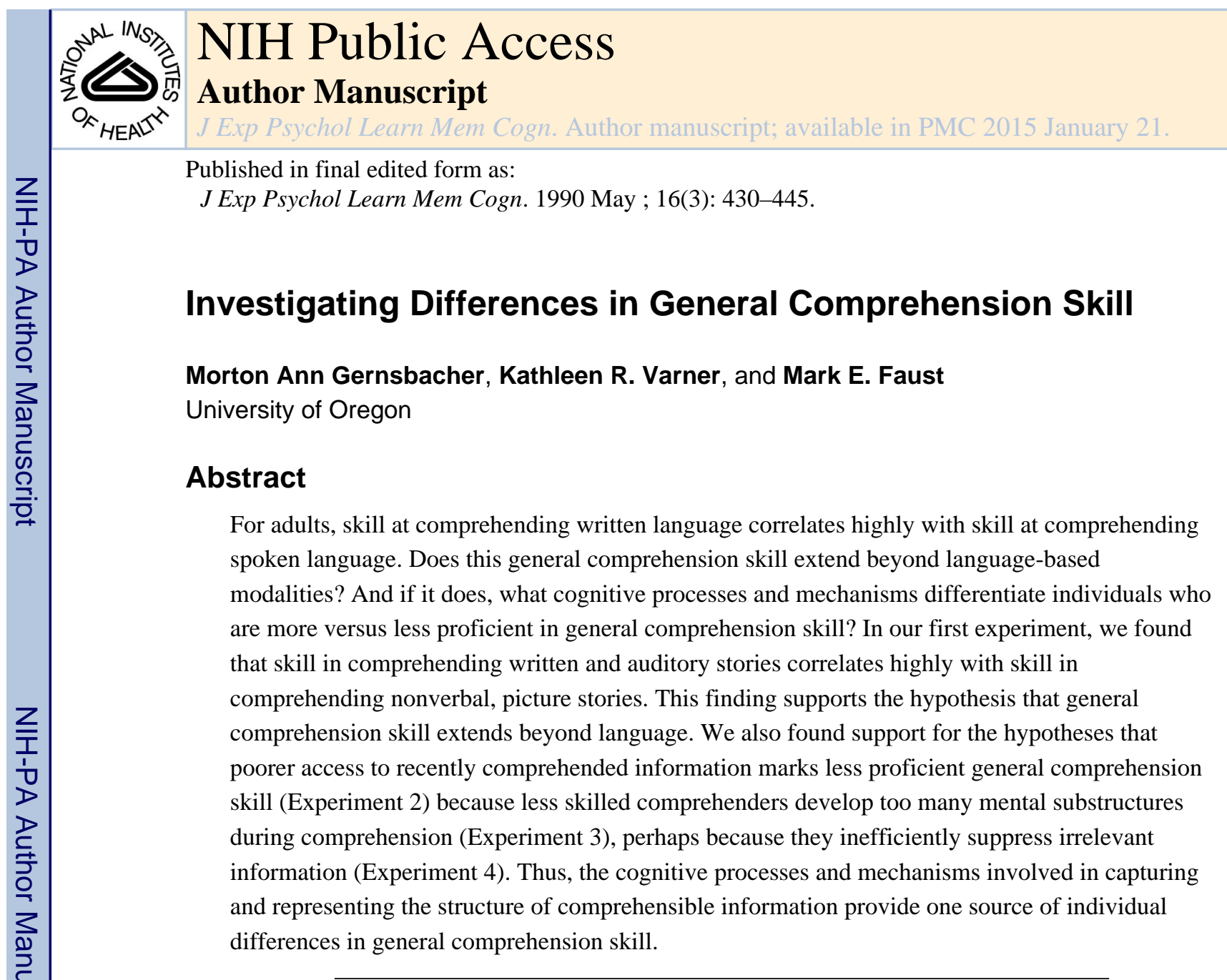

Individuals differ in many ways, including comprehension skill. Laboratory research documents these differences. However, the lion's share of this research investigates comprehension of only one modality - namely, the printed word-and individuals who differ at only one stage of skill development-namely, beginning readers. Therefore, it is not too surprising that the processes suggested to underlie differences in comprehension skill are often specific to reading (see excellent reviews by Carr, 1981; Perfetti, 1985).

When considering differences in adult comprehension skill, we can go beyond those sources. At an adult level of proficiency, skill at comprehending written language is strongly related to skill at comprehending auditory language; in other words, reading and listening correlate highly (Baddeley, Logie, Nimmo-Smith, \& Brereton, 1985; Daneman \& Carpenter, 1980; Jackson \& McClelland, 1979; Palmer, MacLeod. Hunt, \& Davidson, 1985; Perfetti \& Lesgold, 1977; Sticht, 1972).

For example, listening comprehension skill, measured by auditorily presenting the comprehension sections of the Davis reading test, correlates .80, .74, and .68 with reading comprehension skill, measured by visually presenting the comprehension sections of the Davis reading test, the Nelson-Denny reading test, and the Washington Pre-College

Copyright 1990 by the American Psychological Association, Inc.

Correspondence concerning this article should be addressed to Morton Ann Gernsbacher, Department of Psychology, University of Oregon, Eugene, Oregon 97403-1227. Electronic mail may be sent to MortonG@ Oregon.Uoregon.Edu. 
Scholastic Aptitude Test, respectively (Palmer et al., 1985). These high correlations between listening and reading suggest a General Comprehension Skill factor that transcends modality (Palmer et al., 1985).

Perhaps General Comprehension Skill transcends language-based modalities; perhaps General Comprehension Skill underlies facility in comprehending nonlinguistic media, too. The similarities between comprehending text-based written or auditory stories and textless movies or picture stories surely suggest this.

For example, comprehenders perceive the same episode structure when they view a narrative as a movie without dialogue as when they hear it as text (Baggett, 1979). They make the same inferences after they view textless cartoon sequences as they make after they read verbal descriptions of those sequences (Baggett, 1975). Comprehenders can judge how plausible a sentence is just as quickly when a picture substitutes for one of the sentence's words as when the sentence contains only words (Potter, Kroll, Yachzel, Carpenter, \& Sherman, 1986). Comprehenders suffer from the same rapid forgetting of recently comprehended information when they view textless picture stories as when they read or hear text-based stories; in all three media, comprehending a new episode exacerbates this rapid forgetting (Gernsbacher, 1985). Furthermore, when comprehenders recall story episodes, they emphasize, forget, and elaborate the same information regardless of whether they originally viewed the story as a movie without dialogue or heard the story as text (Baggett, 1979; see also Poulsen, Kintsch, Kintsch, \& Premack, 1979).

These similarities suggest that many of the cognitive processes involved in comprehending linguistic media are involved in comprehending nonlinguistic media. Such similarities, therefore, suggest the following hypothesis: Skill in comprehending written and auditory stories correlates highly with skill in comprehending picture stories. In other words, General Comprehension Skill might extend beyond language. We tested this hypothesis in the first experiment we report, and we found considerable support for it.

What cognitive processes and mechanisms contribute to General Comprehension Skill? To appreciate the common processes and mechanisms, we must appreciate what is common to comprehensible information across modalities. One commonality is that it is structured; therefore, the cognitive processes and mechanisms that contribute to General Comprehension Skill might have something to do with capturing and representing structure. Some cognitive processes and mechanisms that do just that are part of a simple framework we call the structure building framework (Gernsbacher, in press-a, in press-b).

\section{The Structure Building Framework}

According to the structure building framework, the goal of comprehension is to build a cohesive, mental representation or "structure." The first process involved in building this structure is laying a foundation. The next process involves developing the structure by mapping on incoming information when that information coheres or relates to previous information. However, if the incoming information is less coherent or related, comprehenders employ a different process: They shift to initiate a new substructure. Thus, most representations comprise several branching substructures. 
The building blocks of these mental structures are memory cells. Memory cells are activated by incoming stimuli. Their initial activation forms the foundation of mental structures. Information is often mapped onto a developing structure because the more the incoming information coheres with the previous information, the more likely it is to activate the same or connected memory cells. But the less the incoming information coheres with the previous information, the less likely it is to activate the same or connected memory cells. In this case, the incoming information might activate a different set of cells, and the activation of this other set of cells forms the foundation for a new substructure.

In addition, once memory cells are activated, they can enhance (boost) or suppress (dampen) other cells' activation. In other words, once activated, two mechanisms modulate the memory cells' levels of activation: enhancement and suppression. Presumably, memory cells are enhanced when the information they represent is necessary for further structure building, and they are suppressed when their information is no longer as necessary.

These three structure building processes-laying a foundation for a mental structure, mapping coherent information onto the developing structure, and shifting to initiate a new structure or substructure when the incoming information is less coherent-and these two mechanisms - enhancement of some memory cells and suppression of others-underlie several comprehension phenomena. For example, the process of laying a foundation explains why the first sentence of a paragraph or story episode is read more slowly than later occurring sentences (Haberlandt, 1984). Similarly, the process of laying a foundation explains why the first picture of a picture story or picture story episode is viewed more slowly than later occurring pictures (Gernsbacher, 1983). These effects emerge because comprehenders use initial sentences and pictures to lay foundations for mental structures that represent story episodes or paragraphs. Because laying a foundation consumes additional processing capacity, comprehension slows during the processing of initial sentences and pictures. Indeed, this slowdown doesn't occur if the incoming information doesn't lend itself to building cohesive mental representations-for example, if the stories or paragraphs are self-embedded or scrambled (Greeno \& Noreen, 1974; Kieras, 1978).

The process of laying a foundation also explains why comprehenders are more likely to recall a story episode when cued by the first sentence of the episode than when cued by later occurring sentences (Mandler \& Goodman, 1982). The process of laying a foundation also explains why comprehenders often consider the first sentence of a passage or paragraph as the main idea of the passage, even when the actual theme occurs later (Kieras, 1980). These effects emerge because initial sentences form the foundation of their episode- and paragraph-level structures; therefore, only through these initial sentences can subsequent sentences be represented.

The process of mapping coherent information onto a developing structure or substructure explains why sentences that literally or conceptually repeat a previous word or a phrase-and thereby signal coherence overtly-are read faster than comparable sentences that are not literally or conceptually repetitive (Haviland \& Clark, 1974; Kintsch, Kozminsky, Streby, McKoon, \& Keenan, 1975). The assumption that coherent information is mapped onto the same mental substructure explains why sentences and phrases coreferenced by repetition are 
more likely to be remembered when one phrase cues or primes the recall or recognition of the other; such phrases are also more likely to be "clustered" in comprehenders' recall protocols (Hayes-Roth \& Thorndyke, 1979; Kintsch et al., 1975; McKoon \& Ratcliff, 1980).

The process of shifting from actively building one substructure to initiate another explains why sentences and words that change the ongoing topic, point of view, or setting take substantially longer to comprehend than those that continue it (Daneman \& Carpenter, 1983; Gernsbacher, 1984; Lesgold, Roth, \& Curtis, 1979; Olson, Duffy, \& Mack, 1984). The assumption that information presented before a comprehender shifts is represented in a different substructure than information presented afterward explains why information presented before a change in topic, point of view, or setting is harder to retrieve than information presented afterward (Clements, 1979; Gernsbacher, 1984; Mandler \& Goodman, 1982).

The mechanism of suppression explains why only one meaning of an ambiguous word, such as bug, is available to consciousness-although multiple meanings are often immediately activated (Gernsbacher \& Faust, 1990; Kintsch, 1988; Swinney, 1979; Tanenhaus, Leiman, $\&$ Seidenberg, 1979). ${ }^{1}$ The mechanism of suppression also explains why listeners have greater access to concepts marked with various attention-getting devices, for instance, contrastive stress (Gernsbacher \& Jescheniak, 1989; Gernsbacher \& Shroyer, 1989). And both the mechanisms of suppression and enhancement explain how anaphors (pronouns, repeated noun phrases, and so forth) improve their antecedents' accessibility. Anaphors both enhance their antecedents' activation (Corbett \& Chang, 1983; Dell, McKoon, \& Ratcliff, 1983; Gernsbacher, 1989), and anaphors suppress the activation of other concepts (Gernsbacher, 1989). The net effect of the mechanisms of suppression and enhancement during anaphoric reference is that antecedents are activated at a higher level than other concepts; therefore, they are more accessible.

To summarize, the general cognitive processes and mechanisms identified by the structure building framework account for many comprehension phenomena.

\section{Individual Differences in Structure Building}

How do these general, cognitive processes and mechanisms contribute to General

Comprehension Skill? Put another way, which ones are deficient in less skilled comprehenders? We began to answer this question by tracing whether a "marker" of less proficient reading and listening comprehension also marks less proficient comprehension of nonlinguistic media. The marker, originally identified by Perfetti and his colleagues, is poorer access to recently comprehended information (Perfetti \& Goldman, 1976; Perfetti \& Lesgold, 1977). To be sure, all comprehenders have poor access to recently comprehended information-in particular, recently comprehended superficial, or surface, information (see review in Gernsbacher, 1985). For instance, only 80 syllables after hearing a sentence, the average comprehender is only slightly above chance at identifying the sentence's syntactic

\footnotetext{
${ }^{1}$ There is some question about whether multiple activation occurs before or after lexical access and whether it is due to automatic activation or backward integration (Glucksberg, Kreuz, and Rho, 1986). Here, we are less concerned with how or when multiple meanings become activated than we are with what happens to the irrelevant meanings once activated.
} 
form (Sachs, 1967). The same phenomenon occurs during reading (Sachs, 1974). Moreover, the same phenomenon occurs during nonlanguage-based comprehension (Gernsbacher, 1985). For instance, when comprehending a picture story, like the sequence shown in Figure 1 , all comprehenders have difficulty remembering a recently viewed picture's left/right orientation (e.g., choosing between the two end pictures in Figure 1). So, poor access to recently comprehended information characterizes normal comprehension of both linguistic and nonlinguistic media.

However, less skilled comprehenders have even poorer access to recently comprehended information. And less skilled comprehenders' poorer access to recently comprehended information is demonstrated while they are reading (Perfetti \& Lesgold, 1977), as well as listening (Perfetti \& Goldman, 1976). For instance, when cued with a word that occurred in the previous sentence, less skilled comprehenders are less able to recall the word that followed the cue word. This finding suggests the following hypothesis: Less-skilled comprehenders have poorer access to recently comprehended information while comprehending written, spoken, and picture stories. That is, poorer access to recently comprehended information might mark less proficient General Comprehension Skill. This hypothesis was tested and supported in our second experiment.

Why does poorer access to recently comprehended information mark less proficient General Comprehension Skill? One obvious explanation is that less skilled comprehenders are characterized by smaller memory capacities. But within the normal range of comprehension skill, which is the range we are interested in here, less and more skilled comprehenders are indistinguishable according to traditional short-term memory measures (Daneman \& Carpenter, 1980, 1983; Hunt, Frost, \& Lunnehorg, 1973; Jackson \& McClelland, 1979; Perfetti \& Goldman, 1976).

Instead of viewing poorer access to recently comprehended information as a cause of less proficient General Comprehension Skill, we view it as only a marker. To understand the underlying cause (or causes), we consider why any comprehender loses access to recently comprehended information. According to the structure building framework, this phenomenon results from the cognitive process of shifting: While building mental representations, comprehenders shift from actively building one structure or substructure to initiate another. The process of shifting reduces access to recently comprehended information because information represented in one substructure is most accessible during the active processing of that substructure. Once comprehenders have shifted to initiate a new substructure, information represented in the previous substructure becomes less accessible.

The structure building framework explains why the accessibility of recently comprehended information is affected by its structure, for instance, its episode structure. Indeed, information becomes markedly less accessible after comprehenders encounter a new episode. Often, the structure of the intervening information-independently of the amount of intervening information - affects how accessible the previous information is (Gernsbacher, 1985; Mandler \& Goodman, 1982). According to the structure building framework, comprehenders shift to initiate a new substructure when cued by speakers, writers, and picture story authors that a new topic, point of view, setting, or episode has begun (Baggett, 
1979; Carpenter \& Just, 1977; Gernsbacher, 1984; Halliday, 1967). Comprehenders probably also initiate a new substructure when the information is simply less coherent.

The accessibility of recently comprehended information is also affected by the amount of intervening information. But this could also be due to the information's structure: The more intervening information, the higher the probability of encountering less coherent information and, therefore, the higher the probability that the comprehenders shifted to initiate new substructure.

The structure building framework's explanation for why comprehenders lose access to recently comprehended information overcomes the limitations of three competing explanations. First, because the structure building explanation can account for the phenomenon's occurrence with nonlinguistic media (such as picture stories), it supersedes a pure psycholinguistics explanation. Second, because the structure building framework can explain why the structure—independent of the amount—of information affects accessibility, the structure building explanation supersedes a memory-limitations explanation: Recently comprehended information becomes less accessible because the quantitative or temporal limits of a short-term memory are exceeded. ${ }^{2}$

Third, because the structure building framework predicts that accessibility worsens with less comprehensible (or less coherent) information, it supersedes a recoding explanation:

Recently comprehended information becomes less accessible because, during the course of comprehension, it is recoded into a more meaningful representation. This more meaningful representation is referred to as gist. The recoding explanation, in contrast to the structure building explanation, predicts that the more comprehensible the information, the less accessible it should be-at least in its unrecoded form. This is so because the more comprehensible the information, the higher its probability of being recoded, and recoding into gist is what makes information less accessible (see Gernsbacher, 1985, for an empirical test between the recoding and structure building explanation; see also von Ekhardt \& Potter, 1985, for other empirical evidence against a recoding hypothesis).

However, meshing the structure building framework's explanation of why any comprehender has poor access to recently comprehended information with the finding that less skilled comprehenders have even poorer access, yields the following hypothesis: Lessskilled comprehenders shift too often. Instead of continuing to map incoming information onto the structure that they are developing, less skilled comprehenders might have a tendency to shift and initiate a new substructure. This hypothesis was tested and supported in our third experiment.

\footnotetext{
${ }^{2} \mathrm{~A}$ corollary is often assumed: Information is held in short-term memory until a meaningful unit has been comprehended (such as a phrase, clause, or episode); then, it becomes less accessible. But this assumption undermines the original explanation. All phrases, clauses, sentences and episodes are not the same size; thus, they would not consume the same amount of space or be held for the same period of time. If while waiting for a phrase, clause, sentence, or episode to end, short-term memory can hold a variable amount for a variable period, then why does the information become less accessible? Perhaps the system is so "smart" that when anticipating a time or space limitation it expunges information at a structurally appropriate point. But this leaves us without an a priori specification of how long or how much information can be held and with no causal link.
} 
Why would a greater tendency toward shifting characterize less proficient General Comprehension Skill? According to the structure building framework, the building blocks of mental representations are memory cells. Memory cells are activated by incoming stimuli, and two mechanisms modulate their level of activation: enhancement, which increases activation, and suppression, which dampens it. Presumably, memory cells are enhanced because the information they represent is relevant to the structure being built; memory cells are suppressed when the information they represent is less relevant.

Consider the consequences of a less efficient suppression mechanism. Information that is less relevant or even inappropriate to the developing structure would remain activated. Because this irrelevant information could not be mapped onto the developing structure, its activation might lay the foundation for a new substructure. So, one consequence of an inefficient suppression mechanism would be the development of too many substructures-in other words, one consequence of an inefficient suppression mechanism would be a greater tendency toward shifting. This suggests the following hypothesis: Less-skilled comprehenders are less able to suppress contextually irrelevant information. If less skilled comprehenders are beset by less efficient suppression mechanisms, that would account for their greater tendency toward shifting and their poorer access to recently comprehended information. This fourth hypothesis was tested and supported in our final experiment.

To summarize, in this article we investigate General Comprehension Skill. We do so by first documenting that such a construct exists and then by tracing its underpinnings, with the structure building framework as a guide.

\section{Experiment 1}

We began with the hypothesis that skill in comprehending written and auditory language will correlate highly with skill in comprehending nonlinguistic media. In other words, we began by testing the hypothesis that a General Comprehension Skill factor transcends language-based comprehension. We tested this hypothesis by constructing and administering a Multi-Media Comprehension Battery (Gernsbacher \& Varner, 1988). The battery comprises six stories: Two are presented by written sentences; two are presented by auditory sentences; and two are presented by pictures. After reading, hearing, or viewing each story, subjects answer comprehension questions, similar to what they do when tested with traditional reading or listening comprehension batteries.

\section{Method}

Subjects-Two-hundred seventy University of Oregon undergraduates were paid $\$ 5$ for participating in the 1-hr session. All were native English speakers with normal or correctedto-normal visual acuity and no reported auditory disabilities.

Materials-The Multi-Media Comprehension Battery includes six stories, two of each modality. The two written and the two auditory stories were modified from four international children's stories (Arbuthnot, 1976). We modified the stories by shortening them and replacing all colloquial expressions and low-frequency words with familiar terms. An example story appears in the Appendix. The two picture stories were modified from the 
illustrations in two juvenile books (Barrett \& Barrett, 1969; Calmenson, 1972). Each illustration was photographed and reproduced as a $35-\mathrm{mm}$ color slide.

Procedure-The two written stories were presented first, followed by the two auditory stories, followed by the two picture stories. Each written story was presented on the screens of the subjects' individual computer monitors. Each story was presented line by line until 24 lines had accumulated, and the screen was filled. After a short pause, the 24 lines disappeared, giving the perception that the screen had been erased; then, each of the 24 lines of the next screenful of text began to appear. Each auditory story was previously recorded by a male speaker at a natural speaking rate and played back to the subjects over their individual headphones. Each picture story was projected one slide at a time onto a standardsized projection screen approximately $5 \mathrm{ft}(1.5 \mathrm{~m})$ away from each subject. A Kodak slide projector, yoked to a computer and tachistoscopic shutter, controlled the presentation. Subjects were encouraged to adjust the brightness/contrast on their display monitors, the volume on their headphones, and their distance from the slide projection screen.

The two written stories were each 636 and 585 words long, and both were presented at a rate of 185 words per minute; the two auditory stories were each 958 and 901 words long and presented at a rate of 215 words per minute; the two picture stories were each 31 and 32 pictures long and presented at a rate of one slide per $7.75 \mathrm{~s}$, including the time required by the slide projector to change slides. Each story, therefore, lasted between 3 and $4.5 \mathrm{~min} .{ }^{3}$

Each story was followed by 12 short-answer questions. Some of the questions measured explicit information (e.g., "What was Ike's last name?"), whereas others measured implicit information (e.g., "Why did the store attendant get so frustrated with Hiram?"). Subjects were allowed $20 \mathrm{~s}$ to write their answers to each question. The 12 questions for one of the auditory stories and one of the picture stories appear in the Appendix.

\section{Results}

Each comprehension question was scored on a 3-point scale according to the scoring criteria presented in Gernsbacher and Varner (1988). The scoring criteria for the example auditory story also appear in the Appendix. Twelve judges scored the subjects' answers, with each subject being scored by a pair of judges. Although the pairs of judges who scored the same subject were unaware of each other's scores, they agreed highly: The average correlation between pairs of judges was .993 (range $=.986-.997$ ). For the rare disagreements, the average of the two judges' scores was assigned. Actually, only 240 of the 270 subjects were scored by two judges; the remaining 30 randomly selected subjects were scored by all 12 judges. Cronbach's alpha for this common set of 30 subjects was .987, also demonstrating high interjudge agreement. Means and standard deviations for the subjects' scores on the written, auditory, and picture stories, and for their total scores are shown in Table 1.

To measure the relations between skill at comprehending the different modalities, we computed correlations between pairs of modalities. The correlation between comprehending

\footnotetext{
${ }^{3}$ The written stories were presented at a slow reading pace to avoid the criticism that the less skilled comprehenders did poorly because they didn't have enough time to encode the stories. This rate was slow, but not artificially slow.
} 
written and auditory stories was .92; the correlation between comprehending written and picture stories was .82; and the correlation between comprehending auditory and picture stories was .72 (all correlations were corrected for unreliability). These correlations demonstrate that subjects who are skilled at comprehending one modality are also skilled at comprehending the other two modalities, and vice versa.

To further measure the relations between skill at comprehending the different modalities and to validate the Multi-Media Comprehension Battery, we correlated 223 of our 270 subjects' scores on the battery with their scores on the verbal subtest of the Scholastic Aptitude Test (SAT). (We were not able to do this for all of our subjects because the SAT is not required for admission to the University of Oregon.) The correlation between verbal SAT and comprehending the written, auditory, and picture stories was .64, .57, and .45, respectively. These data also support the hypotheses that skill in comprehending written language correlates with skill in comprehending auditory and picture stories: thus, General Comprehension Skill might extend beyond language.

Finally, to test the existence of a General Comprehension Skill factor, we performed a principal components analysis on the correlation matrix provided by intercorrelating the six stories. The hypothesis of one general factor was clearly supported: When six principal components were extracted, only one component had an eigenvalue greater than 1.0 (the traditional Kaiser, 1958, criterion for reliable factors). This large first principal component's eigenvalue was 3.67, and the other five eigenvalues ranged from 0.53 downward to 0.37 . Furthermore, all six stories loaded highly and comparably on this first principal component.

To summarize, these results clearly support the hypothesis that skill in comprehending written, auditory, and picture stories is highly correlated and that General Comprehension Skill transcends language.

\section{Experiment 2}

After finding support for the construct of General Comprehension Skill, we turned toward investigating its basis. We began by tracing a marker of less proficient reading and listening comprehension. This marker is poorer access to recently comprehended information, in particular, superficial or "surface" information. In our second experiment we tested the hypothesis that this marker characterizes less skilled comprehenders regardless of whether they are comprehending written, auditory, or picture stories.

We tested this hypothesis by selecting two groups from the distribution of subjects tested on the Multi-Media Comprehension Battery. One group was selected from the top third of the distribution; these were our more skilled comprehenders. A second group was selected from the bottom third of the distribution; these were our less skilled comprehenders.

When these more versus less skilled comprehenders returned to the laboratory, both groups comprehended six new stimulus stories, two in each modality. At two points, we measured both groups' access to recently comprehended information. For the written and auditory stories, we measured how well the subjects could identify each sentence's original word order. For instance, we measured how well the subjects could remember that they read or 
heard the sentence "One day a special gift arrived for the little boy" as opposed to the sentence "A special gift arrived for the little boy one day." For the picture stories, we measured how well the subjects could identify each picture's original left/right orientation. For instance, we measured how well the subjects could remember that the picture they viewed was the top of the two rightmost pictures in Figure 1 as opposed to the bottom picture.

We chose to measure how well subjects could remember the pictures' left/right orientation because left/right orientation does not appear to be encoded verbally. For instance, none of the following verbal encoding tasks improve memory for the left/right orientation of pictures: accompanying each picture by a verbal description that makes special reference to its orientation ("small village with mountain range on the left;" Bartlett, Till, Gernsbacher, \& Gorman, 1983); requiring subjects to verbally generate such a description (Bartlett, Till, \& Levy, 1980); requiring subjects to verbally identify an object that should cue each picture's orientation (Bartlett, Gernsbacher, \& Till, 1987); requiring subjects to verbally identify the orientation of this salient object (Bartlett et al., 1987); and requiring subjects to verbally rehearse some or all of this information prior to the test (Bartlett et al., 1980).

Although other recognition tasks not requiring orientation judgments are enhanced by these verbal activities, identifying original left/right orientation is not; therefore, it appears that left/right orientation is typically not encoded verbally.

So, in Experiment 2, we measured how well more skilled versus less skilled comprehenders could access either sentences' original word order or pictures' original left/right orientation. We measured accessibility at two test points: after subjects comprehended each half of a story and after they comprehended an entire story and wrote a summary of it. More specifically, each story was interrupted at its midpoint, and half the sentences or pictures presented up to that point were immediately tested. Then, after the last sentence or picture in each story had been presented, half the sentences or pictures presented in the second half of the story were also immediately tested. Testing at these two points constituted the early test interval. A late test occurred for each story after comprehenders had taken both early tests and written their summaries for that story.

If poorer access to recently comprehended information marks less proficient General Comprehension Skill, then less skilled comprehenders should have poorer access to recently comprehended information while comprehending written, auditory, and picture stories.

\section{Method}

Subjects-Thirty-two subjects, half at each comprehension skill level, were paid $\$ 5$ for their participation.

Materials and design-Our materials included six stimulus stories, two of each modality. They were modified from a series of six picture stories revolving around a young boy and his adventures with his pets (Mayer, 1967, 1969, 1973, 1974; Mayer \& Mayer, 1971, 1975). One of the stories is illustrated in Figure 1. 
The first two and the last two stories in the original series of six picture stories were converted into language in the following way. For each picture, we wrote a pair of sentences. The members of the pair comprised the same words but in different orders. The different orders were created by rearranging clauses, phrases, or modifiers. However, none of the rearrangements affected the meaning of the sentences. For example, the four pictures in Figure 1 might have been converted into the four following sentences (although they were actually presented as pictures as they are from the fourth story in the series):

1. a. One day a special gift arrived for the little boy.

b. A special gift arrived for the little boy one day.

2. a. The turtle, frog, and dog watched as the boy opened it.

b. As the boy opened it, the turtle, frog, and dog watched.

3. a. Feeling very jealous, the frog stood off to the side.

b. The frog stood off to the side, feeling very jealous.

4. a. A new friend, a young little frog, was inside the box.

b. Inside the box was a new friend, a young little frog.

Like these examples, all sentences were 13 syllables long. One version of each story was constructed by randomly selecting one member of each pair of sentences, and the other version was constructed with the remaining members. Thus, the form in which the subjects initially heard or read each sentence was assigned randomly.

The two picture stories were prepared by first photographing the pictures in the story books and then reproducing them as two 35-mm Ektachrome slides. One version of each story was constructed by quasi-randomly selecting half of the pictures and reversing their left/right orientation (compared with the way they appeared in original story book). We say quasirandomly because we worked under the constraint that no more than two consecutive pictures remained in their original orientation or were reversed. We wanted to randomly assign the pictures' initial left/right orientation to preclude subjects' adopting some strategy (e.g., the main character is always on the left). This random assignment didn't disrupt the coherence of the picture stories (as illustrated in Figure 1); in fact, subjects never commented on the random assignment.

Each story was 24 sentences or pictures long, and every sentence or picture was tested. When they were tested, they were presented in the same sequential order as when the subjects originally read, heard, or viewed them (see Bekerian \& Bowers, 1983, for empirical support of this format).

We counterbalanced our materials by manipulating three variables: input version, test version, and test order. Input version refers to the version that each sentence or picture appeared in when the subjects first read, heard, or saw it. For a given sentence or picture, half the subjects of each skill level read, heard, or viewed it originally in one version, and the other half read, heard, or viewed it in its opposite version. Test version refers to which version each sentence or picture appeared in when it was tested. For a given sentence or 
picture, half the subjects of each skill level were tested with the sentence or picture presented in the same version in which it was originally presented (during the story); the other half of the subjects were tested with that sentence or picture in its changed version. Half the sentences or pictures in each story were tested in the same version in which they were originally presented, and half were tested in their changed version.

Test order refers to whether a sentence or picture was tested at the early or late test points. For a given sentence or picture, half the subjects of each skill level were tested with it at the early test points, and the other half were tested with it at the late test point. Half the sentences or pictures in each story were tested at one of that story's early test points, and half were tested at that story's late test point. By counterbalancing these three variables (input version, test version, and test order), we created eight between-subjects materials sets. Two subjects of each skill level were randomly assigned to each material set.

Procedure: Subjects were tested in groups of four, each group corresponding to one of the eight counterbalanced material sets. Subjects were told that they were going to read, hear, or view six related stories: Two would be presented on their individual computer screens, two would be presented over their headphones, and two would be shown on the slide projection screen in front of them. Excerpts from three stories that were unrelated to the experimental stories were presented as examples (one in each modality). Subjects were told that after reading, hearing, or viewing each story, they would write a summary of it. For illustration, the experimenter orally summarized one of the example stories.

Subjects were told that in addition to measuring their understanding of the stories, the experimenter would also be measuring how well they could remember the sentences or pictures that they had just comprehended. A sentence in its two versions and a picture in its two versions were used as illustrations. Subjects were told that during the middle of each story, they would be tested over sentences or pictures they had just comprehended, and at the end of each story, they would again be tested over sentences or pictures they had just comprehended (i.e., sentences or pictures that had been presented since the first test). Subjects were also told that a final test would occur after they had written their summaries and that this last test would cover sentences or pictures that they had comprehended throughout the entire story.

At the beginning of each story, subjects read on their computer screens, heard over their headphones, or viewed a slide presenting the word ready. After the first 12 sentences or pictures in each story had been presented, subjects read, heard, or viewed the word test. At this point, subjects prepared to respond to the next sentence or picture because it was a test item. After subjects were tested on 6 sentences or pictures, they read, heard, or viewed the words The story continues..., and the next sentence or picture resumed the ongoing story. After the last 12 sentences or pictures in each story had been presented, subjects again read, heard, or viewed the word test. Subjects again prepared to respond to the next sentence or picture because it was a test item. They were tested on 6 sentences or pictures. So, subjects were tested immediately after they read, heard, or viewed the first 12 sentences or pictures of each story (i.e., the first half of the story). And they were tested immediately after they read, heard, or viewed the last 12 sentences or pictures of each story (i.e., the last half of the 
story). These two test points composed the data for the early tests. After subjects had taken the second of these two early tests, they read, heard, or viewed the words Please write your summaries. They had $2 \mathrm{~min}$ to write their summaries. At the end of these $2 \mathrm{~min}$, subjects again read, heard, or viewed the word test. Subjects again prepared to respond to the next sentence or picture as a test item. Subjects were then tested over 12 sentences or pictures that hah occurred throughout the story. This last test composed the late test. Subjects responded to all test items by circling one of the phrases, "sure same," "guess same," "guess different," or "sure different."

The first story was a written story, followed by an auditory story, a picture story, another picture story, an auditory story, and a written story. The sentences and pictures were presented at a rate of one every $5 \mathrm{~s}$ while subjects were comprehending the stories and a rate of one every $8 \mathrm{~s}$ while subjects were being tested. For the written sentences, each sentence appeared one at a time on the screen (as opposed to accumulating to fill a screenful as in the Comprehension Battery).

\section{Results}

Figure 2 displays the results of this experiment, expressed in average percent correct. ${ }^{4}$ The more skilled comprehenders are represented by the hashed bars, and the less skilled comprehenders are represented by the unfilled bars. As illustrated across all three panels of Figure 2, the less skilled comprehenders did indeed have poorer access to recently comprehended information, $F(1,30)=10.16, M S_{e}=0.204, p<.003$. As also illustrated within each panel of Figure 2, this was the case in each of the three modalities: written, $F(1$, $30)=12.79, M S_{e}=0.022, p<.001$; auditory, $F(1,30)=3.86, M S_{e}=0.050, p<.05$; and pictures, $F(1,30)=3.58, M S_{e}=0.071, p<.06$. Indeed, there was no interaction between ability (less vs. more skilled comprehenders) and modality $(F<1)$. These results demonstrate that poorer access to recently comprehended information marks less skilled comprehenders regardless of the modality they are comprehending.

In addition, as illustrated across the three panels of Figure 2, the difference between the less and more skilled comprehenders was greater at the early test points, when the average difference was $10 \%, F(1,30)=14.94, M S_{e}=0.215, p<.001$, than at the late test points, when the average difference was $4 \%, F(1,30)=2.80, M S_{e}=0.030, p>.10$. This pattern was manifested in a reliable interaction between comprehension skill and test point, $F(1,30)$ $=7.96, M S_{e}=0.081, p<.001$. This result suggests that less skilled comprehenders lose access to information earlier than more skilled comprehenders. Another explanation is that performance at the late test points was bounded by the "floor." However, in our third experiment, we also found that the difference between the less and more skilled comprehenders was greater at the early than the late test points, even though both test points occurred earlier, and both groups performed about 10 percentage points higher.

\footnotetext{
${ }^{4}$ All results in Experiments 2 and 3 were replicated when we measured performance by a corrected confidence score in which subjects were given 4 points for being correct with high confidence ("sure same" or "sure different"), 3 points for being correct with low confidence ("guess same" or "guess different"), 2 points for being incorrect and lowly confident, and 1 point for being incorrect and highly confident.
} 
Finally, we also tested our subjects' short-term memory capacity, using the traditional measure of forward digit span (as administered in the Wechsler Adult Intelligence Scale). However, as in the many studies we cited earlier, we too found no difference between our more skilled comprehenders' average digit span $(M=7.13 ; S D=1.93)$ and our less skilled comprehenders' average digit span $(M=7.45 ; S D=2.19), t(15)<1$. Thus, our less skilled comprehenders were not characterized by smaller short-term memory capacities.

To summarize, the results of Experiment 2 support the hypothesis that less skilled comprehenders have poorer access to recently comprehended information during the comprehension of written, spoken, and picture stories. ${ }^{5}$

\section{Experiment 3}

After finding that poorer access to recently comprehended information marks less proficient General Comprehension Skill, we began investigating why. According to the structure building framework, all comprehenders lose access to recently comprehended information when they shift to initiate a new substructure. Information represented in one substructure is most accessible during the active processing of that substructure; after a comprehender shifts to initiate a new substructure, information represented in the previous substructure becomes less accessible. Less skilled comprehenders' poorer access to recently comprehended information suggests that they shift too often.

In our third experiment, we tested this hypothesis by selecting two more samples of more and less skilled comprehenders, again from the extreme thirds of the distribution of subjects who had been tested with the Multi-Media Comprehension Battery. As in Experiment 2, when these more and less skilled comprehenders returned to the laboratory to participate in Experiment 3, they too comprehended six stimulus stories, two in each modality. And again we measured their access to recently comprehended information at two test points: after half a story and after an entire story.

Experiment 3, however, included a manipulation that was specifically designed to induce shifting. The manipulation was scrambling the sentences or pictures within a story. So, of the six stories that the subjects comprehended, half were presented in a scrambled order, and half were presented in their normal chronological order. Stories presented in a scrambled order are, by definition, relatively less coherent. And although scrambled stories are comprehensible (Bower, Black, \& Turner, 1979; Kieras, 1978, 1981; Kintsch, Mandel, \& Kozminsky, 1977; Mandler, 1978; Schwartz \& Flammer, 1981; Stein \& Glenn, 1979; Thorndyke, 1977), building a mental structure of a scrambled story should involve

\footnotetext{
${ }^{5}$ A trivial explanation of these results is that we simply selected subjects, according to their Multi-Media Comprehension Battery scores, who were particularly good at memory for exact wording. Although for some of the questions on the Multi-Media Comprehension Battery, more points are given for more precise wording, not all questions are scored that way. For example, in the story presented in the Appendix, Questions 3, 4, 6, 7, and 8 give full credit (3 points) for synonyms, and Question 10 is purely inferential. Of course, the best counters to the criticism that the Multi-Media Comprehension Battery primarily measures memory for wording are the high correlations between the questions asked about the language stories and the questions asked about the picture stories. Obviously, none of the questions asked about picture stories tap memory for exact wording. Furthermore, none of the questions asked about the picture stories tap memory for left/right orientation; this feature also counters the criticism that the more versus less skilled comprehenders were selected for their ability to do well in the type of tasks they had to perform in Experiments 2 and 3 .
} 
considerably more shifting. By presenting half of the stories scrambled and half of the stories in their normal order, we could compare a situation in which we know that all comprehenders have to shift more frequently (during the scrambled stories) to a situation in which we hypothesize that less skilled comprehenders might also be shifting too frequently (during the normal stories).

Method

Subjects—Thirty-two subjects, half at each comprehension skill level, were paid $\$ 5$ for participating.

Materials and design-Our materials included six stories, two of each modality. Unlike Experiment 2, these six stories were not members of a series; they were unrelated to one another. We constructed the two picture stories from the illustrations in two juvenile books (Relf \& DiSalvo, 1982; Peltzman \& Battaglia, 1981). We constructed the two written and the two auditory stories by composing pairs of 15 -syllable sentences that differed only by clause or phrase arrangement. As in Experiment 2, we created two versions of the written and the auditory stories by randomly selecting one member of each pair of sentences. Similarly, we created two versions of the picture stories by quasi-randomly selecting one half of the pictures from each book and reversing their left/right orientation. We created the scrambled versions of each story by arranging its sentences or pictures according to a random number sequence.

Each story was 16 sentences or pictures long, as opposed to 24 sentences or pictures in Experiment 2. Therefore, the early test points (after each half of the story) occurred after only 8 sentences or pictures. We further shortened the interval before the late test points by measuring accessibility before subjects wrote their summaries (as described below).

We counterbalanced our materials by manipulating three variables. Input version and test order were manipulated as they were in Experiment 2. The third variable was story order: For half the subjects of each skill level, the first, third, and fifth stories were presented in their normal order and the second, fourth, and sixth stories were presented scrambled. For the other half of the subjects, the first, third, and fifth stories were presented in their scrambled order and the second, fourth, and sixth stories were presented normally.

Procedure-The procedure was identical to the procedure of Experiment 2, with the following two exceptions. First, subjects were told that some of the stories would be presented in a scrambled order; nevertheless, they were encouraged to comprehend each story as well as possible. Second, the late test points occurred earlier. For each story, this was the sequence of events: Subjects comprehended the first half of the story ( 8 sentences or pictures); they were tested on 4 of those sentences or pictures; they comprehended the second half of the story ( 8 sentences or pictures); they were tested on 4 of those sentences or pictures; they were then tested on the remaining 8 sentences or pictures, and finally, they wrote their summaries. 


\section{Results}

Figure 3 displays the results of this experiment, expressed in average percent correct (see also footnote 3 ). The more skilled comprehenders are again represented by hashed bars, and the less skilled comprehenders by unfilled bars. As illustrated in both panels of Figure 3, the less skilled comprehenders had poorer access to recently comprehended information, $F(1$, $30)=8.73, M S_{e}=0.329, p<.006$. This result replicates Experiment 2 . Again, there was no interaction between ability (less vs. more skilled comprehenders) and modality $(F<1)$.

As illustrated in the top panel of Figure 3, the more and less skilled comprehenders differed reliably at the early test points, $F(1,30)=9,89, M S_{e}=0.323, p<.003$, but not at the late test points, $F(1,30)=2.43, M S_{e}=0.094, p>.12$. This interaction, $F(1,30)=3.47 . M S_{e}=0.082$, $p<.06$, also replicates Experiment 2. Notice that, on the average, the less skilled comprehenders' performance in Experiment 3 was about the same as the more skilled comprehenders' performance in Experiment 2. Indeed, both groups performed about $10 \%$ higher in Experiment 3 than Experiment 2, probably because the test points occurred earlier. Because the two groups still differed more at the early than the late test points, it's unlikely that this finding in Experiment 2 was a floor effect. Rather, this finding in Experiment 2 and its replication in Experiment 3 suggest that less skilled comprehenders lose access to information earlier.

The bottom panel of Figure 3 illustrates the novel finding of Experiment 3. For the more skilled comprehenders, scrambling the stories significantly reduced their access to recently comprehended information, $F(1,15)=10.06, M S_{e}=0.094, p<.006$. However, for the less skilled comprehenders, there was virtually no difference between the scrambled versus normal stories $(F<1)$. In other words, for the less skilled comprehenders, their access to recently comprehended information was just as poor during the normal stories as the scrambled ones.

If we assume that all comprehenders lose access to recently comprehended information because they shift to initiate a new substructure and if we assume that scrambled stories induce all comprehenders to shift frequently, then one interpretation of these data is that less skilled comprehenders shift as frequently when comprehending normal stories as they do when comprehending scrambled stories. Thus, the results of Experiment 3 support the hypothesis that less skilled eomprehenders suffer from shifting too much during ordinary comprehension.

\section{Experiment 4}

After finding support for the hypothesis that a greater tendency toward shifting characterizes less proficient General Comprehension Skill, we turned toward investigating why that is so. One component of the structure building framework suggests a potential deficit: Perhaps less skilled comprehenders have less efficient suppression mechanisms. The consequences of a less efficient, or perhaps simply less rapid, suppression mechanism is that inappropriate information remains activated. Because this information cannot be mapped onto the developing structure, its activation might lay the foundation for a new substructure. This, in turn, would lead to less skilled comprehenders' greater tendency toward shifting. In 
Experiment 4, we tested the hypothesis that less skilled comprehenders are less able to suppress contextually irrelevant information.

We tested this hypothesis by selecting two additional groups of more versus less skilled comprehenders from the extreme thirds of the distribution of subjects tested on the MultiMedia Comprehension Battery. When these subjects returned to the laboratory, they performed a task that we designed to measure how well comprehenders can suppress irrelevant information. What happened was this: Subjects read a sentence, and then they were presented with a test word. Their task was to verify whether the test word matched the meaning of the sentence they just read. On half the trials, the test word did indeed match the meaning, but we were more interested in the trials in which the test word did not match the meaning.

On half of those trials, the last word of the sentence was an ambiguous word, for example, spade, and the test word was a meaning of the ambiguous word that was inappropriate to the context. For example, the test word ace is the inappropriate meaning of the ambiguous word spade in the context

(5) He dug with the spade.

We compared how rapidly subjects verified that a word like ace was not related to the sentence with how rapidly they verified that ace was not related to the same sentence but with the last word replaced by an unambiguous word, for example,

(6) He dug with the shovel.

This comparison gave us a measure of how activated the inappropriate meaning of the ambiguous word was; the slower subjects were to reject ace after the "spade" sentence, the more activated the inappropriate meaning must have been. In other words, the slower subjects were to reject ace after the "spade" sentence, the less able they must have been to suppress the contextually inappropriate meaning. We refer to this measure as how much interference the comprehenders experienced.

We measured interference at two intervals: immediately after subjects finished reading each sentence and $3 / 4 \mathrm{~s}$ later. We predicted that at the immediate interval, both the less and more skilled comprehenders would show interference. This prediction was based on the vast literature demonstrating that immediately after ambiguous words are read, contextually inappropriate meanings are often activated. We particularly expected multiple activation because our task required comprehenders to focus their attention on a subsequent word and attempt to integrate that word into the previous context (Glucksberg, Kruez, \& Rho, 1986; van Petten \& Kutas, 1987). Our novel predictions concerned what would happen after the delayed interval. If the decreased activation of the inappropriate meanings is due to suppression and if this suppression mechanism is less efficient in less skilled comprehenders, then after the delayed interval, the less skilled comprehenders should still be experiencing a significant amount of interference. 


\section{Method}

Subjects—Sixty-four subjects, half at each comprehension skill level, were paid $\$ 5$ for participating.

Materials and design-We constructed our stimuli by first selecting 80 ambiguous words from homograph norms (Cramer, 1970; Kausler \& Kollasch, 1970; Nelson, McEvoy, Walling, \& Wheeler, 1980). We selected each ambiguous word with the constraint that at least two of its meanings were relatively equal in frequency. Then, for each ambiguous word, we constructed two sentences that differed only by their final words. In one sentence, the final word was the ambiguous word (e.g., "He dug with the spade"); in the other sentence, the final word was a different, unambiguous word that was semantically comparable, though not necessarily synonymous (e.g., "He dug with the shovel"). Finally, we selected a test word for each of the 80 ambiguous words. Each test word represented the meaning of the ambiguous word that was not captured in the sentence. For example, the test word ace followed the sentence, "He dug with the spade." The test words were also unrelated to the sentences when the semantically comparable, unambiguous words were the final words (e.g., the test word ace is unrelated to the sentence, "He dug with the shovel"). All sentences were 4 or 5 words long and consisted of simple vocabulary.

We also constructed 80 filler sentences. These sentences were identical in structure to experimental sentences, and the final words for approximately half were ambiguous words. However, these filler sentences differed from the experimental sentences because their test words were related to the sentences' meaning. For example the sentence "She liked the rose" was followed by the test word flower, and the sentence "She dropped the plate" was followed by the test word break. The correct answer to the test words following such filler sentences was yes.

We counterbalanced our materials by manipulating two variables: First, for each experimental sentence, half the subjects of each skill level were presented with the ambiguous word as the final word of the sentence, and the other half were presented with the semantically comparable, unambiguous word as the final word. Second, for each experimental sentence, half the subjects of each skill level were presented with the test word at the immediate interval, and half were presented with it after the delayed interval. By counterbalancing these two variables, we created four between-subjects material sets. Sixteen subjects, 8 of each comprehension skill level, were randomly assigned to each material set.

Procedure-Each trial began with a warning signal, which was a plus sign that appeared for $850 \mathrm{~ms}$ in the center of the screen. Then, each sentence was presented, one word at a time, in the center of the screen, with the successive word replacing the previous one. Each word's presentation duration was a function of its number of characters plus a constant. The constant was $300 \mathrm{~ms}$, and the function was $16.7 \mathrm{~ms}$ per character. The interval between words was $150 \mathrm{~ms}$. After the offset of the final word in each sentence, the test word appeared either $100 \mathrm{~ms}$ later (the immediate interval) or $850 \mathrm{~ms}$ later (the delayed interval). Each test word was capitalized and flanked by a space and two asterisks, for example: ** 
$\mathrm{ACE}^{* *}$. The test words remained on the screen until the subjects responded or until $2 \mathrm{~s}$ elapsed. Subjects responded with their right hand, using their index finger to press a key labeled yes and their middle finger to press a key labeled no. After each trial, the subjects received feedback: They were told whether they were correct, and if correct, they were shown their reaction times.

\section{Results}

Table 2 presents the subjects' mean reaction times on the experimental trials. ${ }^{6}$ From the data presented in Table 2, we computed an interference measure by subtracting the subjects' reaction time to reject test words like ace after ambiguous words (spade) from their reaction time to reject test words like ace after unambiguous words (shovel). Figure 4 displays how much interference the more skilled comprehenders experienced (illustrated by the hashed lines) and how much interference the less skilled comprehenders experienced (illustrated by the unfilled bars) at the two test intervals.

As illustrated in Figure 4, immediately after the more skilled comprehenders read the ambiguous words, they experienced a significant amount of interference, $F(1,31)=16.44$, $M S_{e}=4,5476, p<.0003$. This suggests that at the immediate interval, the inappropriate meanings were highly activated. However, after the 750-ms delayed interval, the more skilled comprehenders were no longer experiencing a reliable amount of interference, $F(1$, $31)=1.64, M S_{e}=822, p>.20$. This suggests that the inappropriate meanings had become considerably less activated—perhaps through the mechanism of suppression.

As also illustrated in Figure 4, the less skilled comprehenders also experienced a significant amount of interference at the immediate interval, $F(1,31)=8.40, M S_{e}=23,743, p<.007$. In fact, the amount of interference experienced immediately by the less skilled comprehenders didn't differ significantly from the amount experienced immediately by the more skilled comprehenders $(F<1)$. But unlike the more skilled comprehenders, the less skilled comprehenders were still experiencing a significant amount of interference after the delayed interval, $F(1,31)=5.13, M S_{e}=22,519, p<.03$. In fact, as illustrated in Figure 4, the less skilled comprehenders were experiencing the same amount of interference after the delayed interval as they experienced at the immediate interval, $F=0$ (and $F[t, 62]=3.20, M S_{e}=$ $15,433, p<.07$, for the three-way interaction among comprehension skill, amount of interference, and test point). Thus, for the less skilled comprehenders, even after $3 / 4 \mathrm{~s}$ the inappropriate meanings were as highly activated as the appropriate meanings.

This last result corroborates the following finding: One second after reading a sentence such as, The man moved the piano, less skilled fifth-grade readers show interference in naming the ink color of a semantically associated but contextually inappropriate word, such as music; in contrast, $1 \mathrm{~s}$ after reading the same sentence, more skilled fifth-grade readers show

\footnotetext{
${ }^{6}$ The more skilled comprehenders responded to the filler sentences (the yes trials) with an average latency of $579 \mathrm{~ms}(S D=83 \mathrm{~ms})$, and the less skilled comprehenders responded to the filler sentences with an average latency of $627 \mathrm{~ms}(S D=133 \mathrm{~ms})$. Keep in mind, however, that these filler sentences were not manipulated in any way (e.g., they were not manipulated across delay, which is the interesting factor for the experimental trials). Neither were the filler sentences specifically designed to test any hypothesis. Therefore, we caution against drawing too many conclusions from these reaction times.
} 
color naming interference to only a contextually relevant word, such as heavy (Merrill, Sperber, \& McCauley, 1981).

To summarize, the results of Experiment 4 support the hypothesis that less skilled comprehenders have less rapid (and therefore less efficient) suppression mechanisms. This, in turn, could lead to their greater tendency toward shifting and their poorer access to recently comprehended information.

\section{Conclusions}

We began by asking the question, does General Comprehension Skill extend beyond language? In our first experiment, we found that, indeed, skill at comprehending linguistic media (written and auditory stories) is highly related to skill at comprehending nonlinguistic media (picture stories).

We then asked, why do individuals differ in General Comprehension Skill? We began to answer this question by tracing whether a marker of less proficient reading and listening comprehension skill also marks less proficient General Comprehension Skill. In our second experiment, we found that poorer access to recently comprehended information does indeed mark less proficient General Comprehension Skill (i.e., less proficient comprehension of written, auditory, and picture stories).

We then asked why might poorer access to recently comprehended information mark less proficient General Comprehension Skill? To answer this question, we drew upon our structure building framework, which proposes that all comprehenders lose access to recently comprehended information when they shift from actively building one substructure and initiate another. This explanation suggests that less skilled comprehenders shift too often; that is, they develop too many substructures. In our third experiment, we found evidence to support this suggestion.

Finally, we asked, why might a greater tendency toward shifting characterize less proficient General Comprehension Skill? To answer this question, we again drew upon the structure building framework, which proposes that mental structures are built by enhancing the activation of relevant information while suppressing the activation of less relevant information. Because all comprehenders shift to initiate substructures when the incoming information seems less cohesive or relevant to the previous information, less skilled comprehenders might shift more frequently because they are less able to suppress irrelevant information. In our final experiment, we found evidence to support this suggestion.

In essence, we have investigated the construct of General Comprehension Skill by using our structure building framework as a guide. In doing this, we identified some of the cognitive processes and mechanisms involved in capturing and representing the structure of comprehensive information, and we suggested that these processes and mechanisms provide at least one source of individual differences in General Comprehension Skill.

We approached our investigation as "levelers" not "sharpeners" (Bartlett, 1932). We purposely searched for processes and mechanisms that could be common to comprehension 
across different modalities, while we specifically ignored processes and mechanisms that are most likely unique to one modality. However, we recognize that some processes and mechanisms contribute exclusively to comprehension of one modality, and deficiencies in those modality-specific processes and mechanisms might affect comprehension of only that modality. For instance, developmental disabilities or neurological insults that affect only the ability to decode letters in text, identify phonemes in speech, or recognize objects in a visual array might affect comprehension of only written, auditory, or pictorial information, respectively.

We also recognize that we gathered evidence of General Comprehension Skill by using very simple narratives. Had our stimuli contained more sophisticated vocabulary, more complex syntax, or more abstract artwork, we might not have observed such striking commonalities. Similarly, we recognize that we investigated differences in General Comprehension Skill within a sample of comprehenders who have slightly more or less of a good thing. Because our subjects were university students, we assume that even our less skilled comprehenders have an adequate level of General Comprehension Skill. Had we sampled a clinical population or had we investigated the development of General Comprehension Skill during youth or its maintenance during aging, we might have garnered less evidence for General Comprehension Skill or been less successful in identifying general cognitive processes and mechanisms that underlie it.

Our conclusions align closely with a theoretical orientation shared by several investigators: Comprehension skill depends on the efficacy of both the products of comprehension processes and the processes themselves (Carpenter \& Just, 1988; Daneman \& Carpenter, 1980, 1983; Daneman, 1987; Perfetti, 1985). The processes we have considered are those involved in structure building; the products are the mental structures that comprehenders build. Less skilled comprehenders are characterized by inefficient processes: They shift too frequently, and they are less adept at suppressing irrelevant information. Less skilled comprehenders are also characterized by inefficient products: Their mental structures are bulkier, less cohesive, and less accessible.

The structure building framework might also guide the exploration of differences in comprehending other modalities than those we examined here. In many domains, comprehension requires building a coherent mental representation of the information. And in many domains, individuals differ in their skill in building this representation.

\section{Acknowledgments}

We conducted this research while supported by National Science Foundation Grant BNS 85-10096 and a University of Oregon Faculty Research Grant; we prepared the manuscript while supported by National Institutes of Health Research Career Development Award KO4-NS-01376 and Air Force Office of Scientific Research Grants 89-0258 and 89-0111 (all grants were awarded to the first author). Scott Lewis and Doug Koida were instrumental in developing the Multi-Media Comprehension Battery, and they served with Cheryl Brown, Nicole Fredeen, Lilly Gille, Bruce Gobeo, Ann McMurdo, Dawn Parker, and Judy Petersen as judges for the Multi-Media Comprehension Battery. Keith Rayner, Chuck Perfetti, and three anonymous reviewers provided excellent feedback on an earlier version of this article. 


\section{Appendix}

\section{Mike Hooter and the Smart Bears in Mississippi}

There are two kinds of bears-smart bears and foolish bears. Folks in Mississippi used to say Mississippi bears were the smartest in the whole U.S.A.

That's what Mike Hooter, the great Bear-Hunter and Preacher of the Magnolia State, used to say when he was alive, and he sure knew all anybody ever knew about bears. Fact is, he was the greatest bear hunter ever was in Mississippi.

Some folks called him Mike Shouter, for he was forever roaring louder than ten waterfalls when he was preaching sermons or when he was arguing about the smartness of the Mississippi bears. Whenever anyone tried to argue about bears, Mike would tell them about Ike Hamberlin and his time with the smart bears.

One time Mike Hooter and Ike Hamberlin were talking about bears, and they decided to go out hunting together. But Ike was monstrously jealous of Mike, so he thought he'd get a head start and go out alone before him. He set out in the early morning, just he and his dogs.

Well, Mike caught wind of this, so he got up early himself that morning, took his twoshooter, and went off looking for Ike. But Mike didn't take his dogs.

After a time he spotted Ike and just followed him for a distance. Ike had gone pretty deep into the woods when his dogs started growling and barking. They heard another kind of deep noise, and their hairs stood straight up their backs like tomcats in a fight.

"Run go get'em," Ike shouted to the dogs. But the dogs wouldn't. They just ran around Ike yapping and crying, as if they were scared to death.

"Sic 'em! Sic 'em!" Ike kept on hollering to the dogs, but they minded him like birds in flight. Mike was watching all the time, wondering what was going to happen next.

Ike was mad as a hornet, but he was trying to keep his temper; he just kept coaxing the dogs to stir up the bear that he knew was in there somewhere. Those dogs just weren't acting natural. Mike was watching, and he even felt kind of sorry for Ike.

After all, there was the man out hunting for bear. And there was a bear just waiting to be got. And there were the bear-hunting dogs who were supposed to be stirring up the bear. But instead of doing their duty as good hunting dogs should, they just kept whining and standing there with their tails between their legs. It sure wasn't right. You'd think a curse had been cast on them.

Ike was fit to be tied. "I'll teach you good-for-nothin' critters to tend to your business as you ought to," he shouted. Then he took his single barrel, leaned it against a tree, and ran to the creek. There he began picking up stones and throwing them at his dogs. Those dogs started howling to the heavens. 
Just then Ike ran out of stones so he turned around to gather some more. As his back was turned, and his dogs were still howling up a storm, there was a sudden crackling and breaking sound coming from the woods. Mike was watching and out came the biggest and most powerful bear he'd ever seen. Ike heard the sound too and figured he must have thrown enough rocks for his bewitched dogs to get on with their business.

So Ike started setting down the stones he wouldn't be needing. But meanwhile this big mean bear had walked clear over to the tree where Ike had sat down his gun. The bear picked it up with his front paws and looked at it. Then he blew into it with some powerful breaths.

Ike turned around just in time to see the bear with his paws on the gun. Ike froze in his boots. His hair stood up on his head, his mouth was wide open, and his eyes were ready to jump out of his head. And Mike, watching, was just as numb.

The bear looked at Ike with a bear grin, then he put the rifle back against the tree, turned around, and walked off.

Ike rushed up to the gun, grabbed it, aimed straight at the bear, and snapped the lock! ... But not a sound came from the trusty old piece. Though there was a sound of laughing afar off. Just then Ike looked down at his feet, and sure enough he was standing in a pile of gunpowder.

Mike, who had been laughing so hard, decided it was time to give himself up. So he went out from his hiding place and told his friend what that smart Mississippi bear had done to his gun. Old Ike didn't think it was quite so funny. But after years of hearing Mike tell the story, Ike would laugh just as hard as any of the other listeners. And he'd laugh particularly hard when Mike would tell the part about when the bear was walking off, and how he stopped to look back at Ike standing there with that good-for-nothing gun, with his good-for-nothing dogs, and how the bear then put one of his front paws up to his face, and thumbed his nose at poor ole Ike.

\section{References}

Arbuthnot, MH. The Arbuthnot anthology of children's literature. Lothrop, Lee, \& Shepard; New York: 1976.

Baddeley A, Logie R, Nimmo-Smith I, Brereton N. Components of fluent reading. Journal of Memory and Language. 1985; 24:119-131.

Baggett P. Memory for explicit and implicit information in picture stories. Journal of Verbal Learning and Verbal Behavior. 1975; 14:538-548.

Baggett P. Structurally equivalent stories in movie and text and the effect of the medium on recall. Journal of Verbal Learning and Verbal Behavior. 1979; 18:333-356.

Barrett, J.; Barrett, R. Old MacDonald had an apartment house. Atheneum; New York: 1969.

Bartlett, FC. Remembering: A study in experimental and social psychology. Cambridge University Press; Oxford: 1932.

Bartlett JC, Gernsbacher MA, Till RE. Retrieval of left-right orientation of pictures. Journal of Experimental Psychology: Learning, Memory, and Cognition. 1987; 13:27-35.

Bartlett JC, Till RE, Gernsbacher MA, Gorman W. Age-related differences in memory for lateral orientation of pictures. Journal of Gerontology. 1983; 38:439-446. [PubMed: 6863856] 
Bartlett JC, Till RE, Levy JC. Retrieval characteristics of complex pictures: Effects of verbal encoding. Journal ol Verbal Learning and Verbal Behavior. 1980; 19:430-449.

Bekerian DA, Bowers JM. Eyewitness testimony: Were we misled? Journal of Experimental Psychology: Learning, Memory, and Cognition. 1983; 9:139-145.

Bower GH, Black JB, Turner TJ. Scripts in memory for text. Cognitive Psychology. 1979; 11:177220.

Calmenson, S. Hiram's red shirt. Golden Press; New York: 1972.

Carpenter, PA.; Just, MA. Integrative process in comprehension. In: LaBerge, D.; Samuels, SJ., editors. Basic processes in reading: Perception and comprehension. Erlbaum; Hillsdale NJ: 1977. p. 217-241.

Carpenter, PA.; Just, MA. The role of working memory in language comprehension. In: Klahr, D.; Kotovsky, K., editors. Complex information processing: The impact of Herbert A. Simon. Erlbaum; Hillsdale, NJ: 1988. p. 31-68.

Carr TH. Building theories of reading ability. Cognition. 1981; 9:73-114. [PubMed: 7196820]

Clements, P. The effects of staging on recall from prose. In: Freedle, RO., editor. New directions in discourse processing. Ablex; Norwood, NJ: 1979. p. 287-330.

Corbett AT, Chang FR. Pronoun disambiguation: Accessing potential antecedents. Memory \& Cognition. 1983; 11:283-294. [PubMed: 6621344]

Cramer, P. A study of homographs. In: Postman, L.; Keppel, G., editors. Norms of word association. Academic Press; New York: 1970. p. 361-382.

Daneman, M. Reading and working memory. In: Beech, JR.; Colley, AM., editors. Cognitive approaches to reading. Wiley; New York: 1987. p. 57-86.

Daneman M, Carpenter PA. Individual differences in working memory and reading. Journal of Verbal Learning and Verbal Behavior. 1980; 19:450-466.

Daneman M, Carpenter PA. Individual differences in integrating information between and within sentences. Journal of Experimental Psychology: Leaming, Memory, and Cognition. 1983; 9:561585 .

Dell GS, McKoon G, Ratcliff R. The activation of antecedent information during the processing of anaphoric reference in reading. Journal of Verbal Leaming and Verbal Behavior. 1983; 22:121132.

Gernsbacher, MA. Memory for the orientation of pictures in nonverbal stories: Parallels and insights into language processing. 1983. Unpublished doctoral dissertation, University of Texas at Austin

Gernsbacher, MA. Proceedings of the sixth annual conference of the Cognitive Science Society. Erlbaum; Hillsdale, NJ: 1984. Cognitive responses to (linguistic) topic changes; p. 83-89.

Gernsbacher MA. Surface information loss in comprehension. Cognitive Psychology. 1985; 17:324363. [PubMed: 25308975]

Gernsbacher MA. Mechanisms that improve referential access. Cognition. 1989; 32:99-156. [PubMed: 2752708]

Gernsbacher, MA,. Cognitive processes and mechanisms in language comprehension: The structure building framework. In: Bower, GH., editor. The psychology of learning and motivation. Academic Press; New York: in press-a

Gernsbacher, MA. Language comprehemion as structure building. Erlbaum; Hillsdale, NJ: in press-b

Gemsbacher, MA.; Faust, M. Fine tuning the activation of lexical representations during comprehension. In: Simpson, GB., editor. Comprehending word and sentence. North-Holland; Amsterdam: 1990.

Gernsbacher, MA.; Jescheniak, S. Cognitive effects of spoken (contrastive) stress; Paper presented at the 30th annual meeting of the Psychonomic Society; Atlanta, GA. Nov. 1989

Gernsbacher MA, Shroyer S. The cataphoric use of the indefinite this in spoken narratives. Memory \& Cognition. 1989; 17:536-540. [PubMed: 2796738]

Gernsbacher, MA.; Varner, KR. The multi-media comprehension battery. University of Oregon, Institute of Cognitive and Decision Sciences; Eugene, OR: 1988. Tech. Rep. No. 88-07 
Glucksberg S, Kruez RJ, Rho SH. Context can constrain lexical access: Implications for models of language comprehension. Journal of Experimental Psychology: Learning, Memory, and Cognition. 1986; 12:323-335.

Greeno JG, Noreen DL. Time to read semantically related sentences. Memory \& Cognition. 1974; 2:117-120. [PubMed: 24214708]

Haberlandt, K. Components of sentence and word reading times. In: Kieras, DE.; Just, MA., editors. New methods in reading comprehension research. Erlbaum; Hillsdale, NJ: 1984. p. 219-242.

Halliday MAK. Notes on transitivity and theme in English: II. Journal of Linguistics. 1967; 3:199244.

Haviland SE, Clark HH. What's new? Acquiring new information as a process in comprehension. Journal of Verbal Learning and Verbal Behavior. 1974; 13:512-521.

Hayes-Roth B, Thorndyke PW. Integration of knowledge from text. Journal of Verbal Learning and Verbal Behavior. 1979; 18:91-108.

Hunt, E.; Frost, N.; Lunneborg, C. Individual differences in cognition: A new approach to intelligence. In: Bower, GH., editor. The psychology of learning and motivation: Advances in research and theory. Academic Press; New York: 1973. p. 87-122.

Jackson MD, McClelland JL. Processing determinants of reading speed. Journal of Experimental Psychology: General. 1979; 108:151-181. [PubMed: 528903]

Kaiser HF. The varimax criterion for analytic rotation in factor analysis. Psychometrika. 1958; 23:187-200.

Kausler DH, Kollasch SF. Word associations to homographs. Journal of Verhal Lrnrning and Verbal Behavior. 1970; 9:444-449.

Kieras DE. Good and bad structure in simple paragraphs: Effects on apparent theme, reading time, and recall. Journal of Verbal Learning and Verbal Behavior. 1978; 17:13-28.

Kieras DE. Initial mention as a signal to thematic content in technical passages. Memory \& Cognition. 1980; 8:345-353. [PubMed: 7421575]

Kieras DE. Component processes in the comprehension of simple prose. Journal of Verbal Learning and Verbal Behavior. 1981; 20:1-23.

Kintsch W. The role of knowledge in discourse comprehension: A construction-integration model. Psychological Review. 1988; 95:163-192. [PubMed: 3375398]

Kintsch W, Kozminsky E, Streby WJ, McKoon G, Keenan JM. Comprehension and recall of text as a function of content variables. Journal of Verbal Learning and Verbal Behavior. 1975; 14:196-214.

Kintsch W, Mandel TS, Kozminsky E. Summarizing scrambled stories. Memory \& Cognition. 1977; 5:547-552. [PubMed: 24203223]

Lesgold AM, Roth SF, Curtis ME. Foregrounding effects in disclosure comprehension. Journal al Verbal Learning and Verbal Behavior. 1979; 18:291-308.

Mandler JM. A code in the node: The use of story schema in retrieval. Discourse Processes. 1978; $1: 14-35$.

Mandler JM, Goodman MS. On the psychological validity of story structure. Journal of Verbal Learning and Verbal Behavior. 1982; 21:507-523.

Mayer, M. A body, a dog, and a frog. Dial Press; New York: 1967.

Mayer, M. Frog, where are you?. Dial Press; New York: 1969.

Mayer, M. Frog on his own. Dial Press; New York: 1973.

Mayer, M. Frog goes lo dinner. Dial Press; New York: 1974.

Mayer, M.; Mayer, M. A body, a dog, a frog, and a friend. Dial Press; New York: 1971.

Mayer, M.; Mayer, M. Onefrogtoo many. Dial Press; New York: 1975.

McKoon G, Ratcliff R. The comprehension processes and memory structures involved in anaphoric reference. Journal of Verbal Learning and Verbal Behavior. 1980; 19:668-682.

Merrill EC, Sperber RD, McCauley C. Differences in semantic encoding as a function of reading comprehension skill. Memory \& Cognition. 1981; 9:618-624. [PubMed: 7329242]

Nelson D, McEvoy CL, Walling JR, Wheeler JW. The University of South Florida homograph norms. Behavior Research Methods \& Instrumentation. 1980; 12:16-37. 
Olson, GM.; Duffy, SA.; Mack, RL. Thinking-out-loud as a method for studying real-time comprehension processes. In: Kieras, DE.; Just, MA., editors. New methods in reading comprehension research. Erlbaum; Hillsdale, NJ: 1984. p. 253-286.

Palmer J, MacLeod CM, Hunt E, Davidson JE. Information processing correlates of reading. Journal of Memory and Language. 1985; 24:59-88.

Peltzman, R.; Battaglia, A. Mr. Bell's fixit shop. Golden Press; New York: 1981.

Perfetti, CA. Reading ability. Oxford Press; New York: 1985.

Perfetti CA, Goldman SR. Discourse memory and reading comprehension skill. Journal of Verbal Learning and Verbal Behavior. 1976; 15:33-42.

Perfetti, CA.; Lesgold, AM. Disclosure comprehension and sources of individual differences. In: Just, MA.; Carpenter, PA., editors. Cognitive processes in comprehension. Erlbaum; Hillsdale, NJ: 1977. p. 141-183.

Potter MC, Kroll JF, Yachzel B, Carpenter E, Sherman J. Pictures in sentences: Understanding without words. Journal of Experimental Psychology: General. 1986; 115:281-194. [PubMed: 2944988]

Poulsen D, Kintsch E, Kintsch W, Premack D. Children's comprehension and memory for stories. Journal of Experimental Child Psychology. 1979; 28:379-403. [PubMed: 533833]

Relf, P.; DiaSalvo, D. That new baby!. Golden Press; New York: 1982.

Sachs JS. Recognition memory for syntactic and semantic aspects of connected discourse. Perception \& Psychophysics. 1967; 2:437-442.

Sachs JS. Memory in reading and listening to discourse. Memory \& Cognition. 1974; 2:95-100. [PubMed: 24214705]

Schwartz MNK, Flammer A. Text structure and title-Effects on comprehension and recall. Journal of Verbal Learning and Verbal Behavior. 1981; 20:61-66.

Stein, NL.; Glenn, CG. An analysis of story comprehension in elementary school children. In: Freedle, RO., editor. New directions in discourse processing. Ablex; Norwood, NJ: 1979. p. 53-120.

Sticht, TG. Learning by listening. In: Freedle, RO.; Carroll, JB., editors. Language comprehension and the acquisition of knowledge. Winston; Washington, DC: 1972. p. 285-314.

Swinney DA. Lexical access during sentence comprehension: (Re)consideration of context effects. Journal of Verbal Learning and Verbal Behavior. 1979; 18:645-659.

Tanenhaus MK, Leiman JM, Seidenberg MS. Evidence for multiple stages in the processing of ambiguous words in syntactic contexts. Journal of Verbal Learning and Verbal Behavior. 1979; 18:427-440.

Thorndyke PW. Cognitive structures in comprehension and memory of narrative discourse. Cognitive Psychology. 1977; 9:77-110.

van Petten C, Kutas M. Ambiguous words in context: An event-related potential analysis of the time course of meaning activation. Journal of Memory and Language. 1987; 26:188-208.

von Ekhardt B, Potter MC. Clauses and the semantic representation of words. Memory \& Cognition. 1985; 13:371-376. [PubMed: 4079753] 

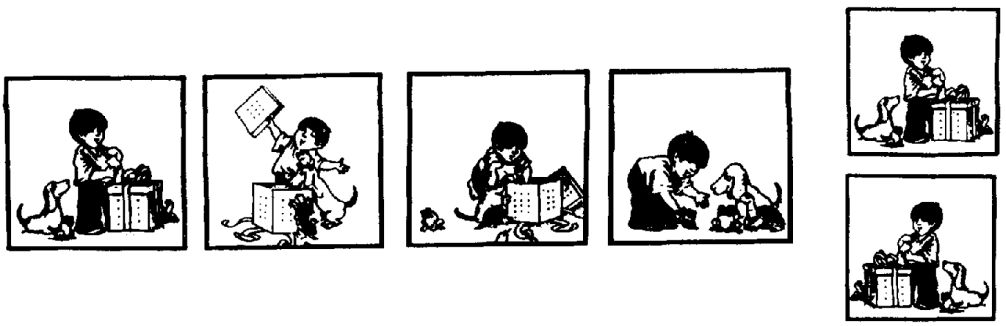

Figure 1.

Example sequence from a picture story with a test picture displayed on the far right in one orientation and its reverse orientation. 


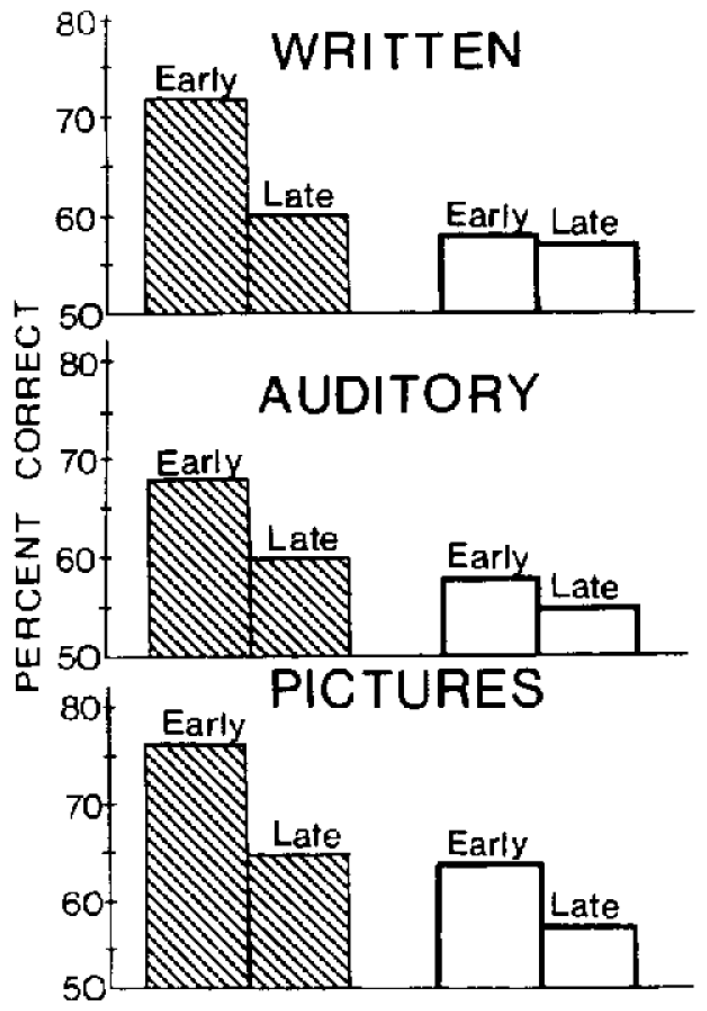

Figure 2.

Subjects' average percent correct in Experiment 2 for each of the three modalities. (The more skilled comprehenders are indicated by the hashed bars, and the less skilled comprehenders by the unfilled bars.) 


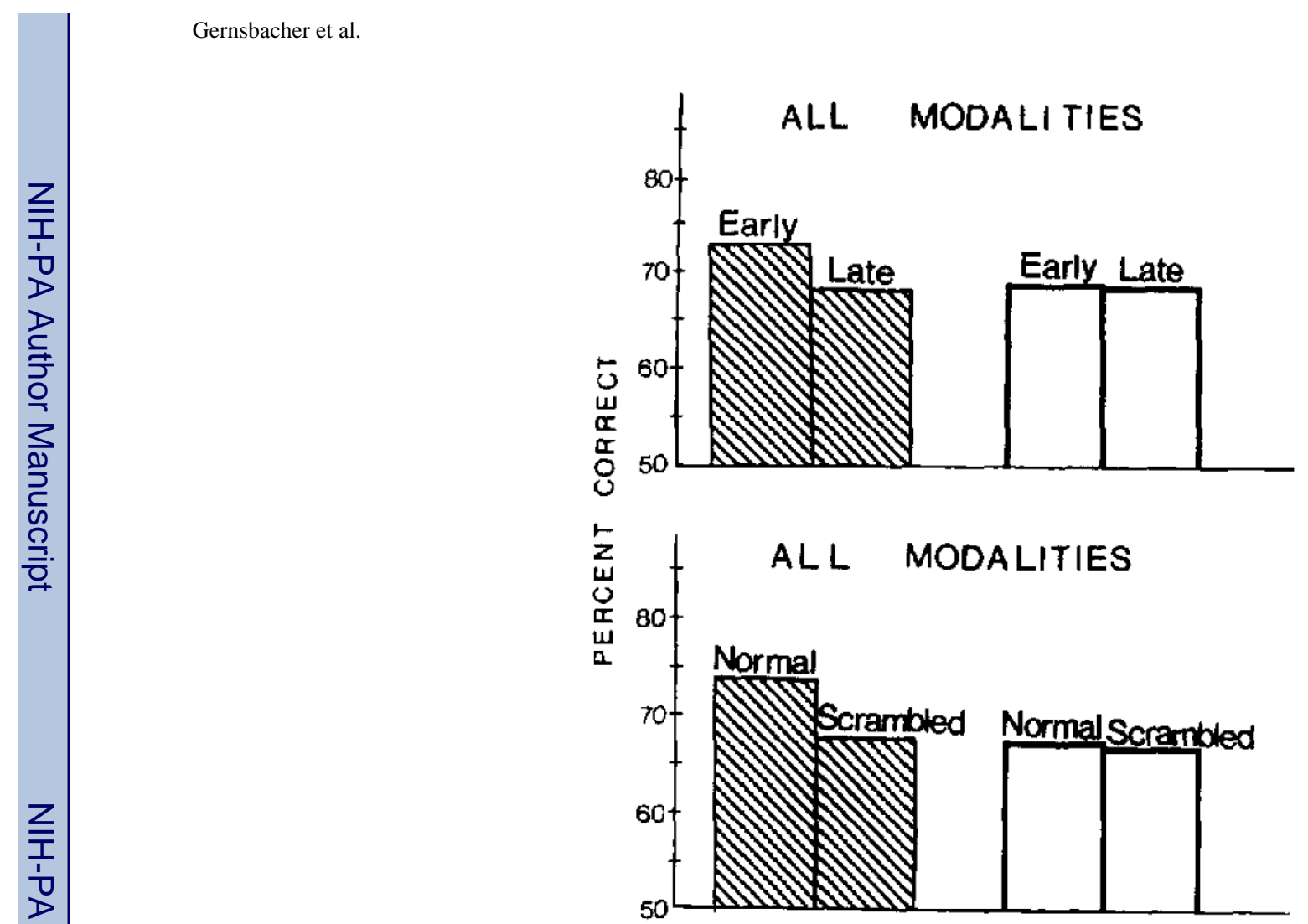

Figure 3.

Subjects' average percent correct in Experiment 3. (The top panel displays the difference between the two test points; the bottom panel displays the effect of the scrambling manipulation. The more skilled comprehenders are indicated by the hashed bars, and the less skilled comprehenders by the unfilled bars.) 


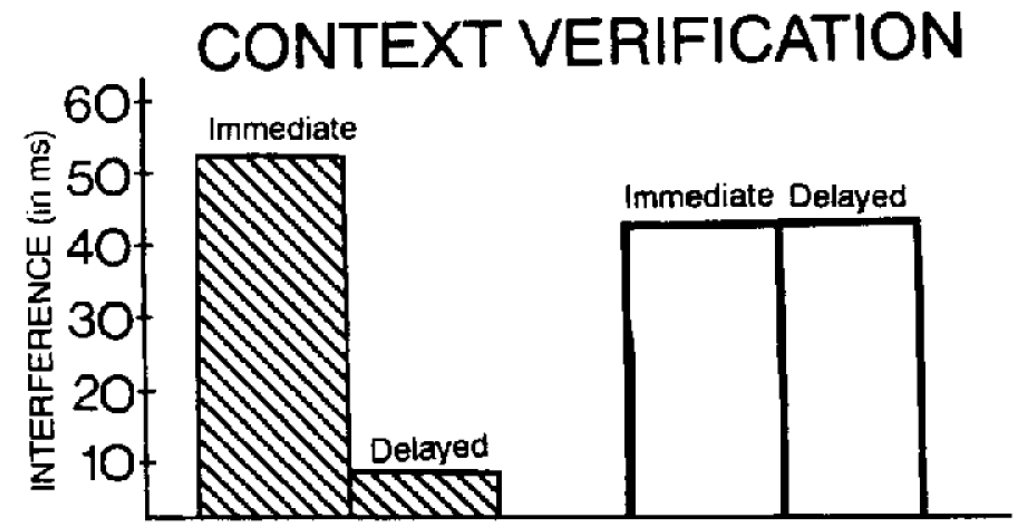

Figure 4.

Subjects' average amount of interference in Experiment 4 (i.e., subjects' latencies to reject the inappropriate meanings of ambiguous words minus their latencies to reject the same words preceded by unambiguous words). (The more skilled comprehenders are indicated by the hashed bars, and the less skilled comprehenders by the unfilled bars.) 
Table 1

Means and Standard Deviations of Subjects' Scores on the Multi-Media Comprehension Battery

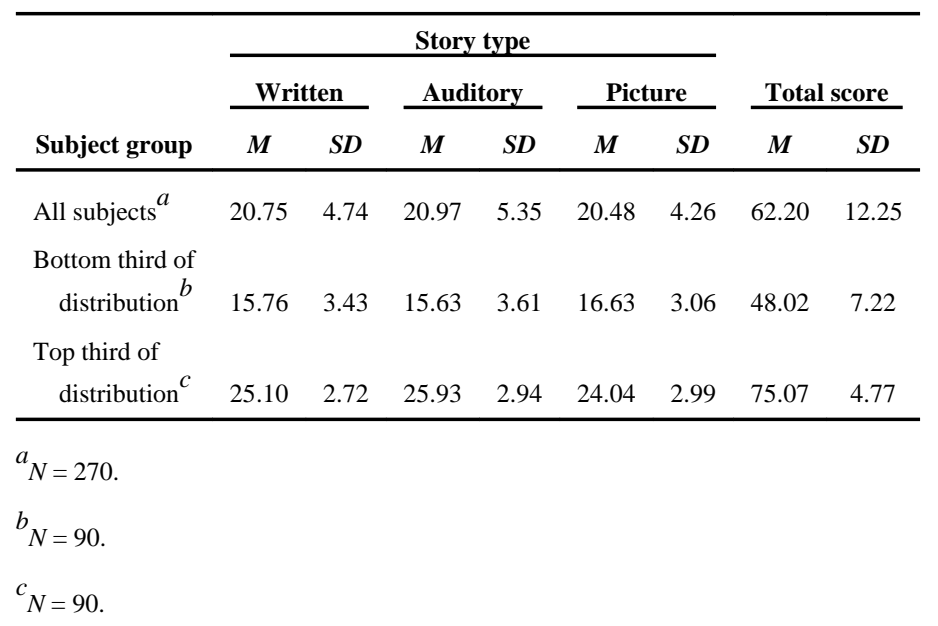


Table 2

Subjects' Mean Reaction Times (in Milliseconds) in Experiment 4

\begin{tabular}{cccccc}
\hline & \multicolumn{5}{c}{ Test interval } \\
\cline { 2 - 3 } \cline { 5 - 6 } $\begin{array}{c}\text { Comprehenders, } \\
\text { skill }\end{array}$ & Ambiguous SFW & Unambiguous SFW & Ambiguous SFW & Unambiguous SFW \\
\cline { 2 - 5 } \cline { 5 - 6 } More skilled & 712 & 659 & 644 & 637 \\
Less skilled & 753 & 713 & & 717 & 677 \\
\hline
\end{tabular}

Note. SFW = sentence-final word. 